\title{
Integrating insights across diverse taxa: challenges for understanding social evolution
}

\author{
Mark A. Elgar * \\ School of BioSciences, University of Melbourne, Melbourne, VIC, Australia
}

Keywords: reproductive altruism, cooperation, polyandry, caste, facultative eusociality, cooperative breeding, social communication, pheromones

OPEN ACCESS

Edited by:

Dustin R. Rubenstein,

Columbia University in the City of

New York, USA

Reviewed by:

Patrizia D'Ettorre,

University Paris 13 - Sorbonne Paris

Cité, France

Heikki Helanterä,

University of Helsinki, Finland

*Correspondence:

Mark A. Elgar

m.elgar@unimelb.edu.au

Specialty section:

This article was submitted to

Social Evolution,

a section of the journal

Frontiers in Ecology and Evolution

Received: 30 March 2015 Accepted: 18 October 2015

Published: 31 October 2015

Citation:

Elgar MA (2015) Integrating insights across diverse taxa: challenges for understanding social evolution.

Front. Ecol. Evol. 3:124.

doi: 10.3389/fevo.2015.00124
While it is broadly true that all sexually reproducing organisms have a "social life" (Trivers, 1985), social behavior outside courting and mating is not the modal animal lifestyle. Nevertheless, there is remarkable phylogenetic breadth and evolutionary convergence of the diverse forms of social behavior (e.g., Wilson, 1975), perhaps helping explain why it has captured the enduring attention of the curious. Social behavior is especially puzzling from an evolutionary perspective in at least two ways. The first reflects a Public Goods or Tragedy of the Commons dilemma (e.g., Rankin et al., 2007): although social individuals can benefit from the underlying cooperation among group members, they are nonetheless susceptible to exploitation. The second perspective, arguably attracting far greater attention, concerns reproductive altruism-the question why individuals might forgo personal reproduction in order to assist the reproductive output of others. These two issues are not mutually exclusive: social systems that involve reproductive altruism are also vulnerable to commons tragedies. Nor are they particular to a given taxonomic group.

An enviably strong theoretical framework guides much of our broad understanding of the evolutionary significance of these and other issues in social behavior, so the devil is in the detailto identify the nature of proximate and ultimate processes responsible for the evolution and maintenance of all manifestations of social behavior. Yet the empirical insights that derive from such investigations seem to be too frequently informed by taxonomically constrained traditions and, as a consequence, advances in the field are surprisingly patchy across different taxa. There are at least three sources of this unevenness: historical contingencies; logistical challenges with data collection; and different evolutionary processes. All are apparent in studies of the evolutionary significance of social behavior. My intention here is to highlight that unevenness, and to encourage a taxonomically more inclusive research agenda, which will guarantee that the conceptual models that attend to the detail are challenged for taxonomic generality. Embracing studies across diverse species, from the "model species" to the bizarre, and ensuring that these empirical insights cut across major taxonomic boundaries will help achieve this goal. For example, our understanding of cooperative breeding in vertebrates is overwhelmingly informed by studies of mammals and birds (despite only $8 \%$ of avian species being cooperative breeders, Jetz and Rubenstein, 2011), and of social behavior in invertebrates by studies of insects. This taxonomic imbalance potentially creates a distorted picture by overshadowing investigations of social behavior in other taxa, such as reptiles (e.g., While et al., 2009; Clark et al., 2012), marine invertebrates (e.g., Duffy et al., 2000) or spiders (e.g., Whitehousel and Lubin, 2005; Yip and Rayor, 2014). Such taxonomic unevenness is not restricted to studies of social evolution: past research into sexual selection through female choice was overwhelmingly dominated by studies of birds, while sexual selection through sperm competition was dominated by studies of insects. The taxonomic divide is less apparent in contemporary studies of sexual selection, although there is an emerging risk of theory being challenged by only a few "model species" (Zuk et al., 2014). 


\section{REPRODUCTIVE ALTRUISM}

Darwin (1859) did not explicitly state the challenge of explaining reproductive altruism, but he certainly recognized the problem that workers "often differ widely in instinct and in structure from both the males and fertile females, and yet, from being sterile, they cannot propagate their kind." For Darwin, the "difficulty, which at first appeared ... fatal to my whole theory" was how the sterile workers "could have transmitted successively acquired modifications of structure or instinct to its progeny." Darwin's Difficulty of Sterile Castes is often interpreted as that of "reproductive altruism" (see Herbers, 2009), but it is clear that he was concerned how selection acts on any trait (including caring for others' offspring) in an organism that does not reproduce (see Ratnieks et al., 2011). The broad solution to his problem emerged some 100 years later.

Following Hamilton (1964a,b, 1972), the role of inclusive fitness, which includes the direct and indirect components of natural selection, has dominated our understanding of the evolution of reproductive altruism, and of sociality more generally (see the Special Issue in Biology Letters, Herbers, 2013). Historically, the genetic component of this conceptual framework attracted far greater interest in empirical studies of social insects than in other taxa (see also Herbers, 2013). Perhaps this is hardly surprising, given the apparently exquisite link between the sex-determining mechanism of hymenopterans, which predisposes a high degree of relatedness between sisters, and the frequency with which eusociality has evolved within that taxon. This meant that, initially, the primary focus of research in social insects, and especially the hymenoptera, was on the underlying genetic conditions, and in particular the degree of relatedness between cooperating individuals. In contrast, research into the costs and benefits component of Hamilton's Rule was a far greater focus for studies of cooperative breeding in vertebrates (see Cockburn, 1998; but see Hatchwell et al., 2014). The taxonomic divide is less apparent now, especially since it became clear that haplodiploidy is not the primary driver of eusociality in the hymenoptera (Gadagkar, 1991), with maternal care and nest defense more likely candidates (see Ross et al., 2013). Nowadays, differences of perspective more obviously reflect the important taxonomic difference in the nature of cooperative behaviors: investigating direct direct fitness and cost/benefit issues are important where no permanent caste division occurs, while genetic considerations become more important in species in which the allocation to a particular caste is permanent. Thus, vertebrate "helpers," capable of breeding, typically characterize the former, while studies of social insects have tended to focus on the highly eusocial species that characterize the latter (e.g., Jetz and Rubenstein, 2011; Bourke, 2014).

Nevertheless, the similarities between cooperatively breeding vertebrates and the primitively social bees and wasps often remain overlooked, despite the successful application of reproductive skew models (see Nonacs and Hager, 2011) as a shared conceptual framework. Empirical research into the evolution of cooperative breeding in vertebrates and invertebrates still seems to proceed largely independently, with reviews of cooperative breeding often retaining a taxonomic focus (but see Russell and Lummaa, 2009; Bourke, 2014; English et al., 2015). Field experiments of insects are often logistically less challenging than for vertebrates, but the insights are no less transferable (e.g., Cockburn et al., 2008; Leadbeater et al., 2011; Schwarz et al., 2011). For example, field experiments on primitively social wasps successfully identified the role of key ecological selection pressures favoring extended care and additional careers (e.g., Field et al., 2000; Field and Brace, 2004). Species that adjust their social behavior facultatively are also ideal for helping us understand the ecological and genetic influences on the evolution of social behavior (e.g., Field et al., 2010; Hatchwell et al., 2013; Rehan et al., 2014; Kapheim et al., 2015b). Jeremy Field and colleagues revealed, through clever field transplant experiments, that eusocial behavior in the sweat bee Halictus rubicundus is more likely if there is more time available for offspring production (Field et al., 2010). These results lend support to the view that iteroparity, rather than semelparity, is the predominant pattern for insects with subsocial behavior (Trumbo, 2013), which is typically regarded as a precursor to eusociality (e.g., Queller and Strassmann, 1998). Maintaining a strong taxonomic focus may also obscure broader patterns. Interestingly, Ben Hatchwell and colleagues long-term study of the facultatively cooperative breeding long-tailed tit Aegithalos caudatus reveals a negative correlation between breeding season length and the number of helpers in the social group (Hatchwell et al., 2013). This apparent inconsistency may derive from the temporal scale of iteropary that reflects different life-cycles: Halictus "non-helpers" breed in the same season as the social bees, but long-tailed tits may be "non-helpers" in order to improve the likelihood of surviving to breed the following season.

The heuristic value of inclusive fitness theory in helping explain the evolution of social behavior, and a raft of other biological adaptations, is widely recognized (e.g., Abbot et al., 2011; Bourke, 2011a,b, 2014). In particular, support comes from many empirical studies of social insects that use genetic and demographic data to test directly Hamilton's Rule (Bourke, 2014), especially when applied to conflicts of interest within social insect societies (Bourke, 2011a; see also Rubenstein, 2012). Perhaps the number of studies might be greater, if there was broader clarity of how inclusive fitness can be measured (see Nonacs and Richards, 2015). But arguably more importantly, Andrew Bourke documents the success of Hamilton's Rule in providing a unifying, cross-taxa framework for identifying the ecological, demographic and physiological processes that are likely to favor various forms of social behavior, including when cooperative behavior is (e.g., Schneider and Bilde, 2008) or is not necessarily restricted to interactions between kin (e.g., Clutton-Brock, 2002; Riehl, 2013).

\section{MATING SYSTEMS}

Indeed, Hamilton's Rule should focus attention on the ecological and life-history traits that influence the elements of the inequality, $r b-c>0$. For example, theoretical modeling has long highlighted how mating systems can have an impact on relatedness (e.g., Crozier and Pamilo, 1996), but subsequent 
empirical investigations seem to have focused more on the outcome for sex allocation, perhaps following Trivers and Hare (1976). Koos Boomsma (2007, 2009, 2013) noted that the evolution of sterile castes is more likely to occur under monandry, since this ensures high levels of within-group relatedness. This view seems to have galvanized a taxonomically integrated investigation, as support is provided by inter-specific comparative studies of insects, birds, and mammals. Hughes et al. (2008) used ancestral state reconstruction to show that monandry was the ancestral state in eight independent lineages leading to the evolution of eusociality in the hymenoptera. Similarly, the non-cooperative breeding ancestors of cooperative breeding birds typically had lower levels of polyandry than noncooperative ancestors of non-cooperative breeders (Cornwallis et al., 2010). Lukas and Clutton-Brock (2012) also report that the evolution of cooperative breeding in mammals was confined to socially monogamous species, whose offspring are likely to be close kin since socially monogamous species are typically not polyandrous. The consistency of these patterns across these major taxonomic groups is impressive, especially because each study used slightly different methods, reflecting in part the different logistical challenges of data collection in different taxonomic groups. For example, Hughes et al. (2008) inferred the mating system of species from genetic data, while Lukas and Clutton-Brock (2012) inferred it primarily from behavioral data. Cornwallis et al. (2010) obtained a continuous measure of polyandry, inferred from genetic data, whereas Hughes et al. (2008) distinguished between monandry and polyandry according to whether the female mated with fewer or more than two males respectively. The patterns for vertebrates are interesting because the mating system is expected to specifically influence the evolution of eusociality (Boomsma, 2007), which Hughes et al. (2008) tested by comparing species in which workers are totipotent (can reproduce) or not. It is, perhaps, intriguing that such relaxed definitions of monogamy yield significant patterns, because even low levels of polyandry will substantially reduce the levels of within-brood relatedness (but see Boomsma and d'Ettorre, 2013).

Perhaps more intriguing, is the absence (or at least very low levels) of polyandry in the ancestors of species with reproductive altruism. The ubiquity of polyandry across multicellular animals suggests that it is the ancestral state, allowing females to exercise strategic, non-random mating decisions to improve their reproductive success (Kvarnemo and Simmons, 2013). Indeed, studies of eusocial insects were amongst the first to identify the benefits of polyandry (e.g., Schmid-Hempel and Crozier, 1999). However, polyandry reduces male fitness through shared paternity, and thus creates a sexual conflict (Arnqvist and Rowe, 2005; Parker and Birkhead, 2013), with maleimposed monandry a widespread, and probably more common, consequence. Monogamy in many parasitoid wasps appears to be male induced (e.g., Leonard and Boake, 2008; Ablard et al., 2011), and in other species is favored when local mating patchiness increases (e.g., Boulton and Shuker, 2015). If monandry is a significant pre-condition of cooperative and eusocial behavior under certain circumstances (see Leggett et al., 2012; Nonacs, 2014), then it would be interesting to know why it occurs, given there is likely to be strong opposing selection as a female mating strategy. Further, the relationship between polyandry (or multiple mating) and mixed parentage is not necessarily straightforward, especially if there is an element of cryptic female choice (e.g., Den Boer et al., 2010; Pryke et al., 2010; Boomsma, 2013; Kvarnemo and Simmons, 2013). Indeed, the term promiscuous, frequently used in the context of polyandry and social behavior, may be unhelpful as it conflates the nature (discriminating or not) with the frequency of mating (Elgar et al., 2013), thereby obscuring the importance of female and male mating strategies in the evolution of mating systems (e.g., Leggett et al., 2012). In any event, monandry is unlikely to have evolved as a mechanism to promote social behavior, and as Boomsma (2013) wisely counsels, we require a much richer understanding of the interplay between female mating and parental care strategies across the taxonomic spectrum.

These phylogenetic analyses also highlight the multiple losses of cooperative or social breeding in diverse species (e.g., Danforth et al., 2003, 2013; Hughes et al., 2008; Cornwallis et al., 2010). Investigations of the evolutionary loss of social behavior could provide significant insights, but remarkably this has not been a fashionable field of investigation (see Kranz et al., 2002; Beauchamp, 2004; Liebert et al., 2005; Jiricny et al., 2014). As already mentioned above, studies of facultative reproductive altruism are likely to be helpful, as it is possible to investigate simultaneously the factors favoring a loss or gain in social behavior.

\section{PHYLOGENIES, GENOMICS AND INSIGHTS INTO SOCIAL EVOLUTION}

Comparative analyses have been a powerful analytic tool for studies of social evolution, and the current armory of molecular genetic techniques provide further exciting opportunities to address a range of issues (Evans and Wheeler, 2001; Page and Amdam, 2007; Danforth et al., 2013). For example, differences in gene expression and DNA methylation across different castes in social insects are providing remarkable insights into how the interplay between genes and environment cause both caste differentiation and subsequent behavioral plasticity (see Linksvayer et al., 2012; Libbrecht et al., 2013; Yan et al., 2015). Linking population-wide variation in social behavior (Kocher et al., 2015) with genomics may provide rich insights into the separate and combined influences of genetic and environmental factors on social behavior (Kocher et al., 2013), and their consequences for other life history attributes. Inter-specific comparisons of the genome sequences of bees with varying complexity of social behavior reveal that while independent evolutionary transitions to eusociality have different genetic underpinnings, they nonetheless increase in the complexity of gene networks (Kapheim et al., 2015a). A fascinating comparative transcriptome-wide analysis of single representatives of bees, ants and wasps reveals that the convergent evolution of caste determination across these lineages involves similar metabolic pathways and molecular functions, but not exactly the same genes (Berens et al., 2015). The importance of social communication 
is highlighted by Zhou et al. (2015), whose comparison of the chemoreceptor genomes of a solitary wasp, a facultatively eusocial halictid bee and several species of ants revealed positive selection on these chemoreceptor genes.

The recent publication of almost 50 avian genomes, representing at least one species of all avian orders (see Jarvis et al., 2014; Zhang et al., 2014), will likely ensure that we can similarly draw on a rich diversity of avian species, rather than focus on a few model systems.

\section{COOPERATION BEYOND REPRODUCTION}

My focus thus far has been on the varying manifestations of reproductive altruism, perhaps reflecting the majority interest in this form of social behavior. Indeed, the term social insect seems to have a rather specific meaning-namely those species that exhibit varying levels of reproductive altruism-despite the diversity of social behaviors among insects and other invertebrates that fall outside the traditional classifications that emphasize parent-offspring interactions (e.g., Wilson, 1971, 1975; Choe and Crespi, 1997; Costa, 2006; Székely et al., 2010). While these aggregations can have defensive properties (Costa, 2006), they may also involve subtle levels of cooperation over foraging: for example, aggregations of many insect larvae comprise leaders and followers, with the former initiating movement of the group from their roosting to foraging sites. Leadership behavior occurs in diverse social organizations across the taxonomic spectrum, and is thought to improve the efficiency of group decision-making (Conradt and Roper, 2007; King and Cowlishaw, 2009). Drawing on insights from across these social organizations has proved helpful. Leadership in some species is despotic (e.g., King et al., 2008), suggesting the benefits of leadership may come at a cost to followers. However, consensual leadership in social insects benefits the following workers, through the collective success of the colony (e.g. Seeley, 2010). The latter highlights how our understanding of consensual leadership requires consideration of the benefits of leadership to followers. For example, leaders of foraging aggregations of the steel-blue sawfly Perga affinis do not have higher growth rates than followers, but individual sawflies in experimental groups comprising leaders and followers have higher growth rates than those in groups of either only leaders or only followers (Hodgkin et al., 2014).

Social behavior involves cooperation, which is inevitably vulnerable to exploitation. For example, the benefits that individuals in a group obtain from their collective foraging activities will be diminished if some individuals do not forage but rather depend on the searching skills of others (Barnard and Sibly, 1981). Similarly, the early detection of predators may depend on the corporate vigilance of individuals in the group, but an individual could benefit more by spending less time vigilant, and thus more time foraging, without substantially reducing the likelihood that the group detects the predator (see Elgar, 1989). More complex social systems are similarly vulnerable to exploitation, as Jon Seger so eloquently observed: "insect sociality ... portrays an almost melodramatically volatile politics, in which individuals attempt to gain advantage by taking part in profoundly cooperative relationships, but none the less find themselves constantly tempted to cheat" (Seger, 1991, p. 338).

An extensive body of game theory examines the cooperative resolution of public goods, prisoner's dilemma, and other social games (extensively reviewed in Sigmund, 2010)—far exceeding the number of empirical tests beyond laboratory games involving university students of psychology or business studies. The temptation to cheat occurs in social systems with or without reproductive altruism, and there are both vertebrate and invertebrate examples of behaviors in the former social systems that have evolved apparently in response to these conflicts (e.g. Mulder and Langmore, 1993; Wenseleers and Ratnieks, 2006; Ratnieks and Wenseleers, 2008; Zanette et al., 2012; Fischer et al., 2014). The underlying mechanisms that allow individuals to recognize "cheating" events and respond appropriately have been well documented in social insects, but seem to be less well understood in vertebrate systems. Arguably, more complex mechanisms of recognizing and responding to cheating are expected among those inter-specific cooperative, or mutualistic, associations that involve social behavior (Raihani et al., 2012) such as between ants and the larvae of lycaenid butterflies (e.g., Pierce et al., 2002) or associations involving cleaner fish (Vail et al., 2013). Particularly interesting are those inter-specific systems-from "slave-making ants" (e.g., Buschinger, 2009) to microbes (e.g., Lopez et al., 2011) in which the exploited species is unable to detect or respond to the exploiting species.

Interestingly, microorganisms are emerging as especially tractable model systems to test theoretical accounts of public goods games. The behavior of these organisms has strikingly similar social functions with that of invertebrates and vertebrates, including group hunting, social communication, creation of domiciles and specialized roles (see Crespi, 2001). These systems have provided remarkable accounts of the conflicts and confluences of interest in social organizations (e.g., Jiricny et al., 2010; Strassmann and Queller, 2011; Cordero et al., 2012; Popat et al., 2012; Ghoul et al., 2014; Oliveira et al., 2014), providing insights into the evolution of multicellularity (e.g., Michod and Roze, 2001; Grosberg and Strathmann, 2007; Biernaskie and West, 2015; Levin et al., 2015), and revealing intriguing practical implications (e.g., Leggett et al., 2014; Webster, 2014).

\section{COMMUNICATION, SIGNALS AND CONTROL}

Communication is crucial for cooperative relationships. Broadly, social communication can provide information about individual or group identity, and/or about fitness-relevant traits, such as fertility. At the very least, individuals must produce and perceive signals that identify themselves to appropriate partners. Our understanding of the role of these signals in social behavior varies across taxa. Chemical signals involved in the communication systems of social insects, especially involving individual or colony recognition, have been investigated very extensively (van Zweden and d'Ettorre, 2010; Sturgis and Gordon, 2012; Richard and Hunt, 2013), with varying degrees of experimental rigor (van Wilgenburg and Elgar, 2013). In contrast, fewer studies have 
investigated how cooperative behavior in vertebrates is similarly facilitated by either olfactory (e.g., Mateo, 2003; Charpentier et al., 2010; Le Vin et al., 2010; Krause et al., 2012; Leclaire et al., 2013) or vocal (e.g., Rendall et al., 1996; Sharp et al., 2005; McDonald and Wright, 2011; Keen et al., 2013) recognition cues.

For social insects, arguably the most crucial impact that pheromones can have on fitness-relevant traits is their role in the reproductive division of labor (see Oi et al., 2015a). It is widely understood that queen derived pheromones effectively suppress worker reproduction, and the identity of these pheromones has been identified in several species (e.g., Van Oystaeyen et al., 2014; Oi et al., 2015a). However, there is some lively debate whether these pheromones represent queen control of worker reproduction, against the interests of the workers, or a signal informing the workers of queen's reproductive state and thus colony health (Oi et al., 2015a). These "alternative" positions may, in fact, represent explanations at different levels of analysis (Peso et al., 2015): the strong association between the presence of queen derived pheromone and little, or no, worker reproduction is consistent with the view that, at the proximate level, the pheromone controls the behavior of the workers. However, at the ultimate level, a pheromone that represents a signal against the interests of the receiver will exert strong selection on the receiver to avoid that control. One outcome of the resulting co-evolutionary arms race is a proliferation of diverse "worker control" pheromones-as selection favors modified queen pheromone to counteract selection on worker "resistance" (Peso et al., 2015). Such a diversity of pheromones is not apparent (Holman et al., 2013; van Zweden et al., 2013; Van Oystaeyen et al., 2014; Oi et al., 2015b), suggesting that the pheromone is more likely an honest signal of queen fertility, and the workers respond accordingly.

One surprisingly neglected component of communication concerns the reception capacity of receivers (Gill et al., 2013). Typically, studies of signaling and communication evolution focus on the signal and how it might reflect attributes of the signaler. But communication involves both signalers and receivers, with theory predicting co-evolution between the two. Thus, features of the receiver exert selection on the design of the signal and features of the signal exert selection on the ability of the receiver to detect it, with the latter manifested in the structure of the receptors and/or receptor organs (e.g.,

\section{REFERENCES}

Abbot, P., Abe, J., Alcock, J., Alizon, S., Alpedrinha, J. A. C., Andersson, M., et al. (2011). Inclusive fitness theory and eusociality. Nature 471, E1-E2. doi: 10.1038/nature09831

Ablard, K., Fairhurst, S., Andersen, G., Schaefer, P., and Gries, G. (2011). Mechanisms, functions, and fitness consequences of pre- and post-copulatory rituals of the parasitoid wasp Ooencyrtus kuvanae. Ent. Exp. Appl. 140, 103-111. doi: 10.1111/j.1570-7458.2011.01137.x

Arnqvist, G., and Rowe, L. (2005). Sexual Conflict. Princeton, NJ: Princeton University Press.

Avila, P., and Fromhage, L. (2015). No synergy needed: ecological constraints favor the evolution of eusociality. Am. Nat. 186, 31-40. doi: 10.1086/681637
Endler, 1993). Perhaps social evolution, with its greater reliance on communication, also requires the evolution of increasingly sensitive sensory receptors. For example, the sensory structures of facultatively social species may vary with the complexity of the social organization.

\section{DRIVEN BY THEORY, UNCONSTRAINED BY TAXA}

Our broad understanding of the evolution of social behavior has benefited from an enviably strong, taxonomically unconstrained, conceptual framework that guides empirical studies. New theoretical perspectives continue to emerge (e.g., Port et al., 2011; Van Dyken and Wade, 2012a,b; McGlothlin et al., 2014; Van Cleve and Akçay, 2014; Avila and Fromhage, 2015) as well as new methodological approaches (e.g., Kurvers et al., 2014), and both will undoubtedly guide future avenues for research. And yet, some quite fundamental questions remain-such as why is eusociality so much more prevalent in terrestrial than aquatic or marine ecosystems (Ruxton et al., 2014)? While important discoveries will continue to emerge from studies of model species, our understanding of social evolution will undoubtedly be enriched by studies of both "model" and less fashionable or quirky taxa, and by a far greater integration of these empirical insights across taxonomic divides. Conceptual models should be tested against diverse taxa (and even against different populations of the same species to ensure genuine replication-see Parker and Nakagawa, 2014), and synthetic reviews should be taxonomically inclusive. The challenge for Frontiers in Social Evolution is to facilitate this integration, by providing a taxonomically unconstrained focus on the ideas and empirical insights about the evolution of all manners of social behavior, thereby allowing a richer appreciation of among the most impressive and exquisite consequences of natural selection.

\section{ACKNOWLEDGMENTS}

I thank Dustin Rubenstein, Sebastian Pohl, and the two reviewers for their insightful comments that vastly improved the breadth and quality of this piece, and the Australian Research Council for support (DP120100162).
Barnard, C. J., and Sibly, R. M. (1981). Producers and scroungers - a general model and its application to captive flocks of house sparrows. Anim. Behav. 29, 543-550. doi: 10.1016/S0003-3472(81)80117-0

Beauchamp, G. (2004). Reduced flocking by birds on islands with relaxed predation. Proc. R. Soc. B 271, 1039-1042. doi: 10.1098/rspb.2004.2703

Berens, A. J., Hunt, J. H., and Toth, A. L. (2015). Comparative transcriptomics of convergent evolution: different genes but conserved pathways underlie caste phenotypes across lineages of eusocial insects. Mol. Biol. Evol. 32, 690-703. doi: 10.1093/molbev/msu330

Biernaskie, J. M., and West, S. A. (2015). Cooperation, clumping and the evolution of multicellularity. Proc. R. Soc. B 282, 20151075. doi: 10.1098/rspb.2015.1075

Boomsma, J. J. (2007). Kin selection versus sexual selection: why the ends do not meet. Curr. Biol. 17, R673-R683. doi: 10.1016/j.cub.2007.06.033 
Boomsma, J. J. (2009). Lifetime monogamy and the evolution of eusociality. Phil. Trans. R. Soc. B 364, 3191-3207. doi: 10.1098/rstb.2009.0101

Boomsma, J. J. (2013). Beyond promiscuity: mate-choice commitments in social breeding. Phil. Trans. R. Soc. B 368, 20120050. doi: 10.1098/rstb.2012.0050

Boomsma, J. J., and d'Ettorre, P. (2013). Nice to kin and nasty to non-kin: revisiting Hamilton's early insights on eusociality. Biol. Lett. 9, 20130444. doi: 10.1098/rsbl.2013.0444

Boulton, R. A., and Shuker, D. M. (2015). The costs and benefits of multiple mating in a mostly monandrous wasp. Evolution 69, 939-949. doi: 10.1111/evo.12636

Bourke, A. F. G. (2011a). Principles of Social Evolution. (Oxford: Oxford University Press).

Bourke, A. F. G. (2011b). The validity and value of inclusive fitness theory. Proc. $R$. Soc. B 278, 3313-3320. doi: 10.1098/rspb.2011.1465

Bourke, A. F. G. (2014). Hamilton's rule and the causes of social evolution. Phil. Trans. R. Soc. B 369, 20130362. doi: 10.1098/rstb.2013.0362

Buschinger, A. (2009). Social parasitism among ants: a review (Hymenoptera: Formicidae). Myrmecol. News 12, 219-235.

Charpentier, M. J. E., Crawford, J. C., Boulet, M., and Drea, C. M. (2010). Message 'scent': lemurs detect the genetic relatedness and quality of conspecifics via olfactory cues. Anim. Behav. 80, 101-108. doi: 10.1016/j.anbehav.2010.04.005

Choe, J. C., and Crespi, B. J. (eds.). (1997). Social Behavior in Insects and Arachnids. (Cambridge: Cambridge University Press).

Clark, R. W., Brown, W. S., Stechert, R., and Greene, H. W. (2012). Cryptic sociality in rattlesnakes (Crotalus horridus) detected by kinship analysis. Biol. Lett. 8, 523-525. doi: 10.1098/rsbl.2011.1217

Clutton-Brock, T. (2002). Kin selection and mutualism in cooperative vertebrates. Science 296, 69-72. doi: 10.1126/science.296.5565.69

Cockburn, A. (1998). Evolution of helping behavior in cooperatively breeding birds. Ann. Rev. Ecol. Syst. 29, 141-177. doi: 10.1146/annurev.ecolsys.29.1.141

Cockburn, A., Osmond, H. L., Mulder, R. A., Double, M. C., and Green, D. J. (2008). Demography of male reproductive queues in cooperatively breeding superb fairy-wrens Malurus cyaneus. J. Anim. Ecol. 77, 297-304. doi: $10.1111 / j .1365-2656.2007 .01335 . x$

Conradt, L., and Roper, T. J. (2007). Democracy in animals: the evolution of shared group decisions. Proc. R. Soc. B, 274, 2317-2326. doi: 10.1098/rspb.2007.0186

Cordero, O. X., Wildschutte, H., Kirkup, B., Proehl, S., Ngo, L., Hussain, F., et al. (2012). Ecological populations of bacteria act as socially cohesive units of antibiotic production and resistance. Science 337, 1228-1231. doi: $10.1126 /$ science. 1219385

Cornwallis, C. K., West, S. A., Davis, K. E., and Griffin, A. S. (2010). Promiscuity and the evolutionary transition to complex societies. Nature 466, 969-972. doi: 10.1038 /nature09335

Costa, J. T. (2006). The Other Insect Societies. (Cambridge, MA: Harvard University Press).

Crespi, B. J. (2001). The evolution of social behavior in microorganisms. Trends Ecol. Evol. 16, 178-183. doi: 10.1016/S0169-5347(01)02115-2

Crozier, R. H., and Pamilo, P. (1996). Evolution of Social Insect Colonies: Sex Allocation and Kin-selection. (Oxford: Oxford University Press).

Danforth, B. N., Cardinal, S., Praz, C., Almeida, E. A. B., and Michez, D. (2013). The impact of molecular data on our understanding of bee phylogeny and evolution. Annu. Rev. Entomol. 58, 57-78. doi: 10.1146/annurev-ento-120811153633

Danforth, B. N., Conway, L., and Ji, S. Q. (2003). Phylogeny of eusocial Lasioglossum reveals multiple losses of eusociality within a primitively eusocial clade of bees (Hymenoptera: Halictidae). Syst. Biol. 52, 23-36. doi: $10.1080 / 10635150390132687$

Darwin, C. (1859). On the origin of species. (London: Murray).

den Boer, S. P., Baer, B., and Boomsma, J. J. (2010). Seminal fluid mediates ejaculate competition in social insects. Science 327, 1506-1509. doi: $10.1126 /$ science. 1184709

Duffy, J. E., Morrison, C. L., and Ríos, R. (2000). Multiple origins of eusociality among sponge-dwelling shrimps (Synalpheus). Evolution 54, 503-516. doi: 10.1111/j.0014-3820.2000.tb00053.x

Elgar, M. A. (1989). Predator vigilance and group size in mammals and birds: a critical review of the empirical evidence. Biol. Rev. 64, 13-33. doi: 10.1111/j.1469-185X.1989.tb00636.x

Elgar, M. A., Jones, T. M., and McNamara, K. B. (2013). Promiscuous words. Front. Zool. 10:66. doi: 10.1186/1742-9994-10-66
Endler, J. A. (1993). Some general comments on the evolution and design of animal communication systems. Phil. Trans. R. Soc. B 340, 215. doi: 10.1098/rstb.1993.0060

English, S., Browning, L. E., and Raihani, N. J. (2015). Developmental plasticity and social specialization in cooperative societies. Anim. Behav. 106, 37-42. doi: 10.1016/j.anbehav.2015.05.006

Evans, J. D., and Wheeler, D. E. (2001). Gene expression and the evolution of insect polyphenisms. Bioessays 23, 62-68. doi: 10.1002/1521-1878(200101)23:1<62::AID-BIES1008>3.3.CO;2-Z

Field, J., and Brace, S. (2004). Pre-social benefits of extended parental care. Nature 428, 650-652. doi: 10.1038/nature02427

Field, J., Paxton, R. J., Soro, A., and Bridge, C. (2010). Cryptic plasticity underlies a major evolutionary transition. Curr. Biol. 20, 2028-2031. doi 10.1016/j.cub.2010.10.020

Field, J., Shreeves, G., Sumner, S., and Casiraghi, M. (2000). Insurance-based advantage to helpers in a tropicalhover wasp. Nature 404, 869-871. doi: $10.1038 / 35009097$

Fischer, S., Zöttl, M., Groenewoud, F., and Taborsky, B. (2014). Group-size dependent punishment of idle subordinates in a cooperative breeder where helpers pay to stay. Proc. R. Soc. B 281, 20140184. doi: 10.1098/rspb.2014.0184

Gadagkar, R. (1991). On testing the role of genetic asymmetries created by haplodiploidy in the evolution of eusociality in the Hymenoptera. J. Genet. 70, 1-31. doi: 10.1007/BF02923575

Ghoul, M., West, S. A., Diggle, S. P., and Griffin, A. S. (2014). An experimental test of whether cheating is context dependent. J. Evol. Biol. 27, 551-556. doi: $10.1111 /$ jeb. 12319

Gill, K. P., van Wilgenburg, E., Macmillan, D., and Elgar, M. A. (2013). Density of antennal sensilla influences efficacy of communication in a social insect. Am. Nat. 182, 834-840. doi: 10.1086/673712

Grosberg, R. K., and Strathmann, R. R. (2007). The evolution of multicellularity: a minor major transition? Ann. Rev. Ecol. Evol. Syst. 38, 621-654. doi: 10.1146/annurev.ecolsys.36.102403.114735

Hamilton, W. D. (1964a). The genetical evolution of social behaviour. I. J. Theor Biol. 7, 1-16. doi: 10.1016/0022-5193(64)90038-4

Hamilton, W. D. (1964b). The genetical evolution of social behaviour. II. J. Theor. Biol. 7, 17-52. doi: 10.1016/0022-5193(64)90039-6

Hamilton, W. D. (1972). Altruism and related phenomena, mainly in social insects. Ann. Rev. Ecol. Syst. 3, 192-232. doi: 10.1146/annurev.es.03.110172. 001205

Hatchwell, B. J., Gullett, P. R., and Adams, M. J. (2014). Helping in cooperatively breeding long-tailed tits: a test of Hamilton's rule. Phil. Trans. R. Soc. B 369 20130565. doi: 10.1098/rstb.2013.0565

Hatchwell, B. J., Sharp, S. P., Beckerman, A. P., and Meade, J. (2013). Ecological and demographic correlates of helping behaviour in a cooperatively breeding bird. J. Anim. Ecol. 82, 486-494. doi: 10.1111/1365-2656.12017

Herbers, J. M. (2009). Darwin's 'one special difficulty': celebrating Darwin 200. Biol. Lett. 5, 214-217. doi: 10.1098/rsbl.2009.0014

Herbers, J. M. (2013). 50 years on: the legacy of William Donald Hamilton. Biol. Lett. 9, 214-217. doi: 10.1098/rsbl.2013.0792

Hodgkin, L. K., Symonds, M. R. E., and Elgar, M. A. (2014). Leaders benefit followers in the collective movement of a social sawfly. Proc. R. Soc. B 281, 20141700. doi: 10.1098/rspb.2014.1700

Holman, L., Lanfear, R., and d'Ettorre, P. (2013). The evolution of queen pheromones in the ant genus Lasius. J. Evol. Biol. 26, 1549-1558. doi: $10.1111 /$ jeb. 12162

Hughes, W. O. H., Oldroyd, B. P., Beekman, M., and Ratnieks, F. L. W. (2008). Ancestral monogamy shows kin selection is key to the evolution of eusociality. Science 320, 1213-1216. doi: 10.1126/science.1156108

Jarvis, E. D., Mirarab, S., Aberer, A. J., Li, B., House, P., Li, C., et al. (2014). Wholegenome analyses resolve early branches in the tree of life of modern birds. Science 346, 1320-1331. doi: 10.1126/science.1253451

Jetz, W., and Rubenstein, D. R. (2011). Environmental uncertainty and the global biogeography of cooperative breeding in birds. Curr. Biol. 21, 72-78. doi: 10.1016/j.cub.2010.11.075

Jiricny, N., Diggle, S. P., West, S. A., Evans, B. A., Ballantyne, G., RossGillespie, A., et al. (2010). Fitness correlates with the extent of cheating in a bacterium. J. Evol. Biol. 23, 738-747. doi: 10.1111/j.1420-9101.2010. 01939.x 
Jiricny, N., Molin, S., Foster, K., Diggle, S. P., Scanlan, P. D., Ghoul, M., et al. (2014). Loss of social behaviours in populations of Pseudomonas aeruginosa infecting lungs of patients with cystic fibrosis. PLOS ONE, 9:e83124. doi: 10.1371/journal.pone.0083124

Kapheim, K. M., Nonacs, P., Smith, A. R., Wayne, R. K., and Wcislo, W. T. (2015b). Kinship, parental manipulation and evolutionary origins of eusociality. Proc. $R$. Soc. B 282, 20142886. doi: 10.1098/rspb.2014.2886

Kapheim, K. M., Pan, H., Li, C., Salzberg, S. L., Puiu, D., Magoc, T., et al. (2015a). Genomic signatures of evolutionary transitions from solitary to group living. Science 348, 1139-1143. doi: 10.1126/science.aaa 4788

Keen, S. C., Meliza, C. D., and Rubenstein, D. R. (2013). Flight calls signal group and individual identity but not kinship in a cooperatively breeding bird. Behav . Ecol. 24, 1279-1285. doi: 10.1093/beheco/art062

King, A. J., and Cowlishaw, G. (2009). Leaders, followers and group decisionmaking. Commun. Integr. Biol. 2, 147-150 doi: 10.4161/cib.7562

King, A. J., Douglas, C. M. S., Huchard, E., Isaac, N. J. B., and Cowlishaw, G. (2008). Dominance and affiliation mediate despotism in a social primate. Curr. Biol. 18, 1833-1838. doi: 10.1016/j.cub.2008.10.048

Kocher, S. D., Li, C., Yang, W., Tan, H., Yi, S. V., Yang, X., et al. (2013). The genome of a socially polymorphic halictid bee, Lasioglossum albipes. Genome Biol. 14:R142. doi: 10.1186/gb-2013-14-12-r142

Kocher, S. D., Pellissier, L., Veller, C. M., Purcell, J., Nowak, M. A., Chapuisat, M., et al. (2015). Transitions in social complexity along altitudinal gradients reveal a combined impact of altitude and season length on social evolution. Proc. $R$. Soc. B. 281:20140627. doi: 10.1098/rspb.2014.0627

Kranz, B. D., Schwarz, M. P., Morris, D. C., and Crespi, B. J. (2002). Life history of Kladothrips ellobus and Oncothrips rodwayi: insight into the origin and loss of soldiers in gall-inducing thrips. Ecol. Entomol. 27, 49-57. doi: 10.1046/j.13652311.2002.0380a.x

Krause, E. T., Krüger, O., Kohlmeier, P., and Caspers, B. A. (2012). Olfactory kin recognition in a songbird. Biol. Lett. 8, 327-329. doi: 10.1098/rsbl.2011.1093

Kurvers, R. H. J. M., Krause, J., Croft, D. P., Wilson, A. D. M., and Wolf, M. (2014). The evolutionary and ecological consequences of animal social networks: emerging issues. Trends Ecol. Evol. 29, 326-335. doi: 10.1016/j.tree.2014.04.002

Kvarnemo, C., and Simmons, L. W. (2013). Polyandry as a mediator of sexual selection before and after mating. Phil. Trans. Royal Soc. B 368, 20120042. doi: 10.1098/rstb.2012.0042

Leadbeater, E., Carruthers, J. M., Green, J. P., Rosser, N. S., and Field, J. (2011). Nest inheritance is the missing source of direct fitness in a primitively eusocial insect. Science 333, 874-876. doi: 10.1126/science. 1205140

Leclaire, S., Nielsen, J. F., Thavarajah, N. K., Manser, M., and Clutton-Brock, T. H. (2013). Odour-based kin discrimination in the cooperatively breeding meerkat. Biol. Lett. 9, 20121054. doi: 10.1098/rsbl.2012.1054

Leggett, H. C., Brown, S. P., and Reece, S. E. (2014). War and peace: social interactions in infections. Phil. Trans. R. Soc. B 369, 20130365. doi: 10.1098/rstb.2013.0365

Leggett, H. C., El Mouden, C., Wild, G., and West, S. (2012). Promiscuity and the evolution of cooperative breeding. Proc. R. Soc. B 279, 1405-1411. doi: $10.1098 / \mathrm{rspb} .2011 .1627$

Leonard, J. E., and Boake, C. R. B. (2008). Associations between male courtship and female polyandry in three species of wasp, Nasonia (Hymenoptera: Pteromalidae). Anim. Behav. 76, 637-647. doi: 10.1016/j.anbehav.2008.04.013

Le Vin, A. L., Mable, B. K., and Arnold, K. E. (2010). Kin recognition via phenotype matching in a cooperatively breeding cichlid, Neolamprologus pulcher. Anim. Behav. 79, 1109-1114. doi: 10.1016/j.anbehav.2010.02.006

Levin, S. R., Brock, D. A., Queller, D. C., and Strassmann, J. E. (2015). Concurrent coevolution of intra-organismal cheaters and resisters. J. Evol. Biol. 28, 756-765. doi: $10.1111 /$ jeb.12618

Libbrecht, R., Oxley, P. R., Kronauer, D. J. C., and Keller, L. (2013). Ant genomics sheds light on the molecular regulation of social organization. Genome Biol. 14:212. doi: $10.1186 / \mathrm{gb}-2013-14-7-212$

Liebert, A. E., Nonacs, P., and Wayne, R. K. (2005). Solitary nesting and reproductive success in the paper wasp Polistes aurifer. Behav. Ecol. Sociobiol. 57, 445-456. doi: 10.1007/s00265-004-0875-5

Linksvayer, T. A., Fewell, J. H., Gadau, J., and Laubichler, M. D. (2012). Developmental evolution in social insects: regulatory networks from genes to societies. J. Exp. Zool. B Mol. Dev. Evol. 318, 159-169. doi: 10.1002/jez.b.22001
Lopez, M. A., Nguyen, H. T., Oberholzer, M., and Hill, K. L. (2011). Social parasites. Curr. Op. Microbiol. 14, 642-648. doi: 10.1016/j.mib.2011.09.012

Lukas, D., and Clutton-Brock, T. H. (2012). Cooperative breeding and monogamy in mammalian societies. Proc. $R$ Soc. B 279, 2151-2156. doi: 10.1098/rspb.2011.2468

Mateo, J. M. (2003). Kin recognition in ground squirrels and other rodents. J. Mammal. 84, 1163-1181. doi: 10.1644/BLe-011

McDonald, P. G., and Wright, J. (2011). Bell miner provisioning calls are more similar among relatives and are used by helpers at the nest to bias their effort towards kin. Proc. R. Soc. B 278, 3403-3411. doi: 10.1098/rspb.2011.0307

McGlothlin, J. W., Wolf, J. B., Brodie, E. D. III, and Moore, A. J. (2014). Quantitative genetic versions of Hamilton's rule with empirical applications. Phil. Trans. R. Soc. B 369, 20130358. doi: 10.1098/rstb.2013.0358

Michod, R. E., and Roze, D. (2001). Cooperation and conflict in the evolution of multicellularity. Heredity 86, 1-7. doi: 10.1046/j.1365-2540.2001.00808.x

Mulder, R. A., and Langmore, N. E. (1993). Dominant males punish helpers for temporary defection in superb fairy-wrens. Anim. Behav. 45, 830-833. doi: 10.1006/anbe.1993.1100

Nonacs, P. (2014). Resolving the evolution of sterile worker castes: a window on the advantages and disadvantages of monogamy. Biol. Lett. 10, 20140089. doi: 10.1098/rsbl.2014.0089

Nonacs, P., and Hager, R. (2011). The past, present and future of reproductive skew theory and experiments. Biol. Rev. 86, 271-298. doi: 10.1111/j.1469185X.2010.00144.X

Nonacs, P., and Richards, M. H. (2015). How (not) to review papers on inclusive fitness. Trends Ecol. Evol. 30, 235-237. doi: 10.1016/j.tree.2015.02.007

Oi, C. A., Van Oystaeyen, A., Oliveira, R. C., Millar, J. G., Kevin, J., Verstrepen, K. J., et al. (2015b). Dual effect of wasp queen pheromone in regulating insect sociality. Curr. Biol. 25, 1638-1640. doi: 10.1016/j.cub.2015.04.040

Oi, C. A., van Zweden, J. S., Oliveira, R. C., Van Oystaeyen, A., Nascimento, F. S., and Wenseleers, T. (2015a). The origin and evolution of social insect queen pheromones: novel hypotheses and outstanding problems. Bioessays 37 , 808-821. doi: 10.1002/bies.201400180

Oliveira, N. M., Niehus, R., and Foster, K. R. (2014). Evolutionary limits to cooperation in microbial communities. Proc. Natl. Acad. Sci. U.S.A. 111, 17941-17946. doi: 10.1073/pnas.1412673111

Page, R. E. Jr., and Amdam, G. V. (2007). The making of a social insect: developmental architectures of social design. Bioessays 29, 334-343. doi: 10.1002/bies.20549

Parker, G. A., and Birkhead, T. R. (2013). Polyandry: the history of a revolution Phil. Trans. R. Soc. B 368, 20120335. doi: 10.1098/rstb.2012.0335

Parker, T. H., and Nakagawa, S. (2014). Mitigating the epidemic of type I error: ecology and evolution can learn from other disciplines. Front. Ecol. Evol. 2:76. doi: 10.3389/fevo.2014.00076

Peso, M., Elgar, M. A., and Barron, A. B. (2015). Pheromonal control: reconciling physiological mechanism with signalling theory. Biol. Rev. 90, 542-559. doi: $10.1111 /$ brv. 12123

Pierce, N. E., Braby, M. F., Heath, A., Lohman, D. J., Mathew, J., Rand, D. B., et al. (2002). The ecology and evolution of ant association in the Lycaenidae (Lepidoptera). Ann. Rev. Entomol. 47, 733-771. doi: 10.1146/annurev.ento.47.091201.145257

Popat, R., Crusz, S. A., Messina, M., Williams, P., West, S. A., and Diggle, S. P. (2012). Quorum-sensing and cheating in bacterial biofilms. Proc. R. Soc. B 279, 4765-4771. doi: 10.1098/rspb.2012.1976

Port, M., Kappeler, P. M., and Johnstone, R. A. (2011). Communal defense of territories and the evolution of sociality. Amer. Nat. 178, 787-800. doi: $10.1086 / 662672$

Pryke, S. R., Rollins, L. A., and Griffith, S. C. (2010). Females use multiple mating and genetically loaded sperm competition to target compatible genes. Science 329, 964-967. doi: 10.1126/science.1192407

Queller, D. C., and Strassmann, J. E. (1998). Kin selection and social insects. Bioscience 48, 165-175. doi: 10.2307/1313262

Raihani, N. J., Thornton, A., and Bshary, R. (2012). Punishment and cooperation in nature. Trends Ecol. Evol. 27, xxx. doi: 10.1016/j.tree.2011.12.004

Rankin, D. J., Bargum, K., and Kokko, H. (2007). The tragedy of the commons in evolutionary biology. Trends Ecol. Evol. 22, 643-651. doi: 10.1016/j.tree.2007.07.009 
Ratnieks, F. L. W., Foster, K. R., and Wenseleers, T. (2011). Darwin's special difficulty: the evolution of "neuter insects" and current theory. Behav. Ecol. Soc. Biol. 65, 481-492. doi: 10.1007/s00265-010-1124-8

Ratnieks, F. L. W., and Wenseleers, T. (2008). Altruism in insect societies and beyond: voluntary or enforced? Trends Ecol. Evol. 23, 45-52. doi: 10.1016/j.tree.2007.09.013

Rehan, S. M., Richards, M. H., Adams, M., and Schwarz, M. P. (2014). The costs and benefits of sociality in a facultatively social bee. Anim. Behav. 97, 77-85. doi: 10.1016/j.anbehav.2014.08.021

Rendall, D., Rodman, P. S., and Emond, R. E. (1996). Vocal recognition of individuals and kin in free-ranging rhesus monkeys. Anim. Behav. 51, 1007-1015. doi: 10.1006/anbe.1996.0103

Richard, F. -J., and Hunt, J. H. (2013). Intracolony chemical communication in social insects. Insect. Soc. 60, 275-291. doi: 10.1007/s00040-013-0306-6

Riehl, C. (2013). Evolutionary routes to non-kin cooperative breeding in birds. Proc. R. Soc. B 280, 20132245. doi: 10.1098/rspb.2013.2245

Ross, L., Gardner, A., Hardy, N., and West, S. A. (2013). Ecology, not the genetics of sex determination, determines who helps in eusocial populations. Curr. Biol. 23, 2383-2387. doi: 10.1016/j.cub.2013.10.013

Rubenstein, D. R. (2012). Family feuds: social competition and sexual conflict in complex societies. Phil. Trans. R. Soc. B 367, 2304-2313. doi: 10.1098/rstb.2011.0283

Russell, A. F., and Lummaa, V. (2009). Maternal effects in cooperative breeders: from hymenopterans to humans. Phil. Trans. R. Soc. B 364, 1143-1167. doi: 10.1098/rstb.2008.0298

Ruxton, G. D., Humphries, S., Morrell, L. J., and Wilkinson, D. M. (2014). Why is eusociality an almost exclusively terrestrial phenomenon? J. Anim. Ecol. 83, 1248-1255. doi: 10.1111/1365-2656.12251

Schmid-Hempel, P., and Crozier, R. H. (1999). Polyandry versus polygyny versus parasites. Phil. Trans. R. Soc. B, 354, 507-515. doi: 10.1098/rstb.1999.0401

Schneider, J. M., and Bilde, T. (2008). Benefits of cooperation with genetic kin in a subsocial spider. Proc. Natl. Acad. Sci. U.S.A. 105, 10843-10846. doi: 10.1073/pnas.0804126105

Schwarz, M. P., Tierney, S. M., Rehan, S. M., Chenoweth, L. B., and Cooper, S. J. B. (2011). The evolution of eusociality in allodapine bees: workers began by waiting. Biol. Lett. 7, 277-280. doi: 10.1098/rsbl.2010.0757

Seeley, T. D. (2010). Honeybee Democracy. (Princeton, NJ: Princeton University Press).

Seger, J. (1991). "Cooperation and conflict in social insects," in Behavioural Ecology: an Evolutionary Approach, 3rd Edn., eds J. R. Krebs and N. B. Davies (Oxford: Blackwells), 338-373.

Sharp, S. P., McGowan, A., Wood, M. J., and Hatchwell, B. J. (2005). Learned kin recognition cues in a social bird. Nature 434, 1127-1130. doi: 10.1038 /nature 03522

Sigmund, K. (2010). The Calculus of Selfishness. (Princeton, NJ: Princeton University Press).

Strassmann, J., and Queller, D. C. (2011). Evolution of cooperation and control of cheating in a social microbe. Proc. Natl. Acad. Sci. U.S.A. 108, 10855-10862. doi: 10.1073/pnas.1102451108

Sturgis, S. J., and Gordon, D. M. (2012). Nestmate recognition in ants (Hymenoptera: Formicidae): a review. Myrmecol. News 16, 101-110.

Székely, T., Moore, A. J., and Komdeur, J. (2010). Social Behaviour: Genes, Ecology and Evolution. (Cambridge: Cambridge University Press).

Trivers, R. L. (1985). Social Evolution. (San Francisco, CA: Benjamin/Cummings Co).

Trivers, R. L., and Hare, H. (1976). Haplodiploidy and the evolution of the social insects. Science 191, 249-263. doi: 10.1126/science.1108197

Trumbo, S. T. (2013). Maternal care, iteroparity and the evolution of social behavior: a critique of the semelparity hypothesis. Evol. Biol. 40, 613-626. doi: 10.1007/s11692-013-9237-4

Vail, A. L., Manica, A., and Bshary, R. (2013). Referential gestures in fish collaborative hunting. Nat. Commun. 4:1765. doi: 10.1038/ncomms 2781

Van Cleve, J., and Akçay, E. (2014). Pathways to social evolution: reciprocity, relatedness, and synergy. Evolution 68, 2245-2258. doi: 10.1111/evo.12438
Van Dyken, J. D., and Wade, M. J. (2012a). Origins of altruism diversity I the diverse ecological roles of altruistic strategies and their evolutionary responses to local competition. Evolution 66, 2484-2497. doi: 10.1111/j.15585646.2012.01630.x

Van Dyken, J. D., and Wade, M. J. (2012b). Origins of altruism diversity II: runaway coevolution of altruistic strategies via "reciprocal niche construction". Evolution 66, 2498-2513. doi: 10.1111/j.1558-5646.2012.01629.x

Van Oystaeyen, A., Oliveira, R. C., Holman, H., van Zweden, J. S., Romero, C., Oi, C. A., et al. (2014). Conserved class of queen pheromones stops social insect workers from reproducing. Science 343, 287-290. doi: 10.1126/science.1244899 van Wilgenburg, E., and Elgar, M. A. (2013). Confirmation bias in studies of nestmate recognition: a cautionary note for research into the behaviour of animals. PLoS ONE 8: e53548. doi: 10.1371/journal.pone.0053548

van Zweden, J. S., Bonckaert, W., Wenseleers, T., and d'Ettorre, P. (2013). Queen signaling in social wasps. Evolution 68, 976-986. doi: 10.1111/evo.12314

van Zweden, J. S., and d'Ettorre, P. (2010). "Nestmate recognition in social insects and the role of hydrocarbons," in Insect Hydrocarbons: Biology, Biochemistry, and Chemical Ecology, eds G. J. Blomquist, A.-G. Bagnéres (Cambridge: Cambridge University Press), 222-243.

Webster, N. S. (2014). Cooperation, communication, and co-evolution: grand challenges in microbial symbiosis research. Front. Microbiol. 5:164. doi: 10.3389/fmicb.2014.00164

Wenseleers, T., and Ratnieks, F. L. W. (2006). Comparative analysis of worker reproduction and policing in eusocial hymenoptera supports relatedness theory. Am. Nat. 168, E163-E179. doi: 10.1086/508619

While, G. M., Uller, T., and Wapstra, E. (2009). Family conflict and the evolution of sociality in reptiles. Behav. Ecol. 20, 245-250. doi: 10.1093/beheco/arp015

Whitehouse, M. E. A., and Lubin, Y. (2005). The functions of societies and the evolution of group living: spider societies as a test case. Biol. Rev. 80, 347-361. doi: $10.1017 /$ S1464793104006694

Wilson, E. O. (1971). Insect Societies. Cambridge: Harvard University Press.

Wilson, E. O. (1975). Sociobiology: The New Synthesis. Cambridge: Harvard University Press.

Yan, H., Bonasio, R., Simola, D. F., Liebig, J., Berger, S. L., and Reinberg, D. (2015). DNA methylation in social insects: how epigenetics can control behavior and longevity. Annu. Rev. Entomol. 60, 435-452. doi: 10.1146/annurev-ento010814-020803

Yip, E. C., and Rayor, L. S. (2014). Maternal care and subsocial behaviour in spiders. Biol. Rev. 89, 427-449. doi: 10.1111/brv.12060

Zanette, L. R. S., Miller, S. D. L., Faria, C. M. A., Almond, E. J., Huggins, T. J., Jordan, W. C., et al. (2012). Reproductive conflict in bumblebees and the evolution of worker policing. Evolution 66, 3765-3777. doi: 10.1111/j.15585646.2012.01709.x

Zhang, G., Li, C., Li, Q., Li, B., Larkin, D. M., Lee, C., et al. (2014). Comparative genomics reveals insights into avian genome evolution and adaptation. Science 346, 1311-1320. doi: 10.1126/science. 1251385

Zhou, X., Rokas, A., Berger, S. L., Liebig, J., Ray, A., and Zwiebel, L. J. (2015). Chemoreceptor evolution in hymenoptera and its implications for the evolution of eusociality. Genome Biol. Evol. 7, 2407-2416. doi: 10.1093/gbe/evv149

Zuk, M., Garcia-Gonzalez, F., Herberstein, M. E., and Simmons, L. W. (2014). Model systems, taxonomic bias, and sexual selection: beyond Drosophila. Annu. Rev. Entomol. 59, 321-338. doi: 10.1146/annurev-ento-011613-162014

Conflict of Interest Statement: The author declares that the research was conducted in the absence of any commercial or financial relationships that could be construed as a potential conflict of interest.

Copyright (c) 2015 Elgar. This is an open-access article distributed under the terms of the Creative Commons Attribution License (CC BY). The use, distribution or reproduction in other forums is permitted, provided the original author(s) or licensor are credited and that the original publication in this journal is cited, in accordance with accepted academic practice. No use, distribution or reproduction is permitted which does not comply with these terms. 